\section{Ingestion of a Mouthpiece Fragment during Sedated Upper Gastrointestinal Endoscopy}

Intravenous sedation prior to upper gastrointestinal endoscopy is widely used. However, it has varying risks, especially cardiopulmonary complications in deeply sedated patients [1]. A paradoxical reaction to a sedative, with the development of emotional lability, agitation, and even rage instead of a calming effect [2], occurs with benzodiazepines in as many as $29 \%$ of patients; $7 \%$ of these are severe reactions [3]. A paradoxical reaction to midazolam may respond very well to flumazenil administration [4]. We describe the case of a man who ingested the tongue depressor portion of a mouthpiece during sedated upper gastrointestinal endoscopy.

A 41-year-old man was referred for the removal of an endoscopic mouthpiece fragment. The patient had visited a private clinic for sedated upper gastrointestinal endoscopy because of epigastric discomfort. The patient had no specific previous history, such as liver disease or cardiopulmonary disease. The patient was given an intravenous injection of $3 \mathrm{mg}$ of midazolam and the mouthpiece was inserted. This was a recently developed fully biodegradable product made of a starch component. The patient had seemed to be slightly irritable, making an attempt to spit out the mouthpiece during the endoscopic procedure. There were no abnormal findings in the stomach and esophagus, and the endoscope was removed from the body. After the procedure, the doctor found that the tongue depressor fragment of the mouthpiece had been lost, and confirmed inges-

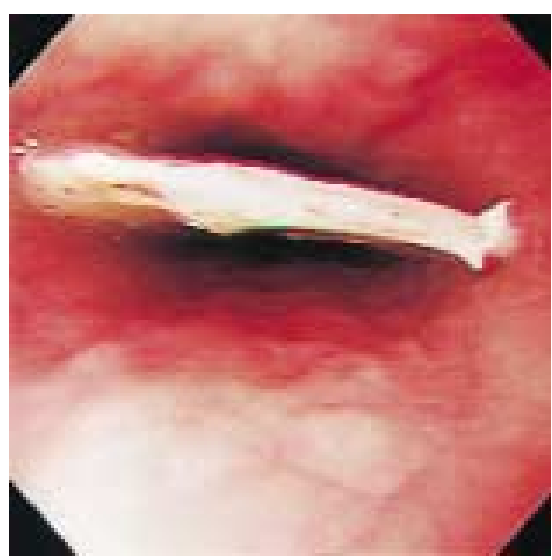

Figure 1 The endoscopic appearance of the mouthpiece fragment in the distal esophagus

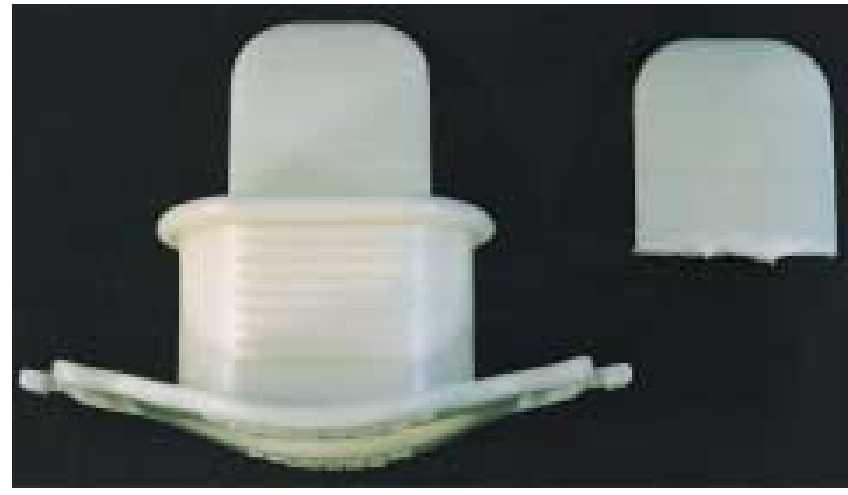

Figure 2 Comparison of the removed mouthpiece fragment with an intact mouthpiece

tion by the patient by means of oral cavity examination and endoscopic evaluation.

Therapeutic upper gastrointestinal endoscopy disclosed a mouthpiece fragment wedged in the distal esophagus (Figure 1). To avoid upper esophageal sphincter injury, a sclerotherapy balloon was attached to the band section of the endoscopy, and then the mouthpiece fragment was removed using a large diameter snare with an inflated sclerotherapy balloon (Figure 2). No serious problem was subsequently encountered except for a mild injury of the upper esophageal sphincter mucosa

This case emphasizes an uncommon but potential complication of sedated upper gastrointestinal endoscopy. In an upper gastrointestinal endoscopic procedure with sedation, the endoscopist and nursing team must closely observe the status of the patient and the mouthpiece to avoid unexpected complications.

\section{S.-O. Lee, S. T. Lee}

Division of Gastroenterology,

Dept. of Internal Medicine,

Chonbuk National University

Medical School, Chonju, Korea

\section{References}

${ }^{1}$ Bell GD. Premedication, preparation, and surveillance. Endoscopy 2000; 32 $92-100$

${ }^{2}$ Short TG, Forrest P, Galletly DC. Paradoxical reactions to benzodiazepine - a genetically determined phenomenon? Anaesth Intensive Care 1987; 15: 330331

${ }^{3}$ Minocha A, Srinivasan R. Conscious sedation: pearls and perils. Dig Dis Sci 1998; 43: 1835-1844

${ }^{4}$ Fulton SA, Mullen KD. Completion of upper endoscopic procedures despite paradoxical reaction to midazolam: a role for flumazenil? Am J Gastroenterol 2000; 95: 809-811

Corresponding Author

S. T. Lee, M.D.

Division of Gastroenterology

Dept. of Internal Medicine

Chonbuk National University

Medical School

634-18, Keum-am dong

Tok-chin gu, Chonju

Chonbuk 561-712, Korea

Fax: $\quad+82-63-2501609$

E-mail: soo@moak.chonbuk.ac.kr 